ISSN 1991-8631

Original Paper

http://indexmedicus.afro.who.int

\title{
Antioxidant and antimicrobial properties of marine actinomycetes from sipadan Island, Sabah
}

\author{
Muhammad bin Abdullah Bukhari AIZUDDIN, Nestor Thomas ATHENA \\ and Wong NYET KUI * \\ Biotechnology Programme, School of Science and Technology, University of Malaysia Sabah, 88400 Kota \\ Kinabalu, Sabah, Malaysia. \\ *Corresponding author, E-mail: nkwong@ums.edu.my; Tel: +6088320771, Fax: +6088435324
}

\begin{abstract}
Marine actinomycetes have great potential as producers of unique bioactive compounds due to its special adaptation in the harsh environment in the ocean. In this study, 100 strains of actinomycetes were isolated from marine sponges collected from sea area close to Sipadan Island in Sabah. Each strain was fermented in mannitol-peptone broth and the secondary metabolites were extracted by using acetone. The secondary metabolites were tested for their antimicrobial and antioxidant activity. The data showed that 22 strains exhibited potent antioxidant activity (IC50 between 56.3 and $99.1 \mu \mathrm{g} / \mathrm{ml}$ ) in DPPH assay and 31 strains have strong inhibition activity $(8 \mathrm{~mm}$ to $19 \mathrm{~mm}$ ) on test pathogens (Bacillus cereus, Bacillus subtilis, Staphylococcus aureus, Streptococcus pyogenes, Escherichia coli, Klebsiella spp., Streptococcus pneumonia and Pseudomonas aeruginosa) in antimicrobial assay. These results give evidence that it is essential to scrutinize these under explored marine microbes in search of new drugs which have great potential to be used in the pharmaceutical fields.

(c) 2013 International Formulae Group. All rights reserved.
\end{abstract}

Keywords: Sipadan island, sponges, marine actinomycetes, antioxidant, antimicrobial.

\section{INTRODUCTION}

Actinomycetes have been the best source for novel drug's discovery. This is why these microbes are regarded as the most prized microbes in the pharmaceutical field, notable for its antibiotic production (Brun et al., 2000; Berdy, 2005, Atta et al., 2010). The enormous therapeutic potentials of actinomycetes are closely related to its abilities to produce secondary metabolites for its survival, in which most of it are rich in bioactive compounds (Lam, 2006; Kekuda et al., 2010;
Naine et al., 2011). Natural products of actinomycetes are critically important for the development of new drugs. Therefore, it has caught the attention of many researchers to explore various environments in search for rare actinomycetes.

Malaysia is a tropical country located in southeast Asia, one of the regions with the most extensive coastline in the world (Carpenter and Springer, 2005). Being surrounded by approximately $9,323 \mathrm{~km}$ of coastline, Malaysia has many beautiful 
islands, in which most of them are important tourism spots due to their conserved environment. In particular, Sipadan Island at the southeast coast of Sabah, is well known for its diverse marine biodiversity due to its location at the heart of Indo-Pacific basin, which is the centre of one of the richest marine habitats in the world (Spadi, 2005). Great numbers of marine life are able to colonize this undisturbed environment, due to their adaptation to grow under extreme ocean conditions. It is interesting to note that the chemical constituents of metabolites produced by microorganisms vary greatly as the result of its extreme living environments, suggesting marine actinomycetes might produce different secondary metabolites compared to those of the same species at the less challenging environments.

From our thorough investigations, it has come under the attention that marine actinomycetes have enormous therapeutic potential and could be pharmaceutically exploited as the resources of novel drug's discoveries (Olano, 2009).

The aim of this research was to investigate the antimicrobial and antioxidant properties of marine actinomycetes isolated from sponges collected closed to conserved sea area of Sipadan Island. In this study, the secondary metabolite's extracts from 100 strains of the marine actinomycetes were tested for its potential antimicrobial and antioxidant activities by using disc diffusion methods and 1, 1-diphenyl-2-picrylhydrazyl (DPPH) scavenging activity, respectively.

Both activities have been selected for this study because of their great medicinal relevance. Bacterial infections are increasingly difficult to treat by using most of the currently available antibiotic agents due to the emergence of many antibiotic-resistance pathogens (Tanaka et al., 2006; Sengupta and Chattopadhyay, 2012). On the other hand, the increasing rate of chronic and degenerative diseases such as cancer, arthritis, autoimmune disorders, cardiovascular, acceleration of aging process and neurodegenerative diseases, in which caused by the accumulation of free radicals in the body (Pham-Huy et al., 2008) have urged the need for new antioxidant drugs from these underexplored marine actinomycetes.

\section{MATERIALS AND METHODS}

\section{Methods}

\section{Sample collection}

Marine sponges were collected around Semporna coastal area $\left(4^{\circ} 066^{\prime} 52.92^{\prime \prime} \mathrm{N}\right.$ and $\left.118^{\circ} 38^{\prime} 04^{\prime \prime} \mathrm{E}\right)$. This area is a conserved region that is located of a close distance from Sipadan Island (Figure 1). The samples were taken by scuba diving at depth between 10-15 $\mathrm{m}$. All samples were kept in a sterilized slip bag and stored in $-40{ }^{\circ} \mathrm{C}$ freezer upon arrival at the laboratory.

\section{Actinomycetes isolation}

Approximately $3 \mathrm{~cm}$ of tissue from mesophyll part of sponge was excised and homogenised in $10 \mathrm{ml}$ seawater using sterile mortar. Homogenate serially diluted and plated on starch casein agar (SCA) prepared by using seawater (nalidixic and cycloheximide supplemented). Plates of isolation media were incubated for 3 weeks in the incubator at $28{ }^{\circ} \mathrm{C}$. The resulting colonies on $\mathrm{HV}$ agar were further sub-cultured on oatmeal (OA) agar with pH 7.2.

\section{Determination of actinomycetes by non- staining КОH method}

A drop of $3 \%$ aqueous $\mathrm{KOH}$ was placed on a slide. Using a sterile loop, a visible amount of bacterial growth is transferred from the agar culture to the drop of $\mathrm{KOH}$. The cells and $\mathrm{KOH}$ were mixed thoroughly on the slide, constantly stirring 
over an area about $1.5 \mathrm{~cm}$ in diameter. If the bacterium-KOH suspension becomes markedly viscid or gels within 5 to 60 seconds, the isolate is Gram negative. If no gelling is observed, the isolate is Gram positive. The best way to test the viscosity is to raise the loop about $1 \mathrm{~cm}$ from the slide. If an obvious stringiness is present, then the culture was gram negative. The actinomycetes can be identified by the sporulation on OA media and also non gelling formation on slides.

\section{Fermentation and extraction}

Productions of microbial secondary metabolites were from actinomycetes grown in $2 \%$ mannitol $+2 \%$ peptone $+1 \%$ glucose liquid medium at $28{ }^{\circ} \mathrm{C}$ for 5 days. The liquid medium was prepared in $100 \%$ seawater. The $25 \mathrm{ml}$ culture in conical flask $(250 \mathrm{ml})$ was shaken at $220 \mathrm{rpm}$ in shake-flask incubator. The secondary metabolites from actinomycetes were extracted by using equal volume of acetone to culture medium.

\section{Antioxidant test.}

Different concentration (100, 50, 25, 12.5 and $6.25 \mu \mathrm{g} / \mathrm{ml}$ ) for each sample were dissolved in water and taken in tubes separately. Ascorbic acid was also prepared in different concentrations (100, 50, 25, 12.5 and $6.25 \mu \mathrm{g} / \mathrm{ml}$ ) and this was used as a reference standard. DPPH (1, 1, Diphenyl-2-Picryl hydrazyl) $0.002 \%$ was freshly prepared in ethanol. DPPH $(2.7 \mathrm{ml})$ was added into each tube containing different concentrations of extracts $(0.3 \mathrm{ml})$ and of standard solution $(0.3$ $\mathrm{ml})$. It was shaken vigorously with a vortex. They were then allowed to stand for 60 minutes for room temperature in dark place.
The control was prepared without any extracts $(0.3 \mathrm{ml}$ water added with $2.7 \mathrm{ml}$ of $0.002 \%$ $\mathrm{DPPH})$. Ethanol was used for base line corrections in absorbance (OD) of sample measured at $517 \mathrm{~nm}$. The below formula was used to interpret the value of the sample.

$\%$ DPPH Scavenging Activity $=[$ (control O.D - sample O.D) / control O.D] x 100

The antioxidant potential of each extract was expressed as IC50 value, indicating the minimal concentration to inhibit $50 \%$ of the DPPH free radicals.

\section{Antimicrobial assay}

Antibacterial activities were assayed by using well diffusion method against the eight standard test organisms namely Bacillus cereus, Bacillus subtilis, Staphylococcus aureus, Streptococcus pyogenes, Escherichia coli, Klebsiella spp., Streptococcus pneumonia and Pseudomonas aeruginosa. The test organisms were grown in sterile nutrient broth at $37{ }^{\circ} \mathrm{C}$ for 12 hours and $200 \mu \mathrm{l}$ of broth containing the test organism is added into $100 \mathrm{ml}$ of priorly autoclaved nutrient agar. Sterile filter paper discs $6 \mathrm{~mm}$ in diameter were impregnated with $20 \mu \mathrm{l}$ of each extract $(30 \mathrm{mg} / \mathrm{ml})$ which were prepared using the same solvents employed to dissolve the extracts, and then sterilized, and placed on the agar surface containing each test organism. Standard 6-mm discs containing chloramphenicol were used as positive controls. Negative controls were made using paper discs loaded with $20 \mu \mathrm{l}$ of the solvents. The plates were incubated overnight at $37{ }^{\circ} \mathrm{C}$ for 18-24 hours. At the end of the incubation period antimicrobial activity was evaluated by measuring the diameter of inhibition zone. 


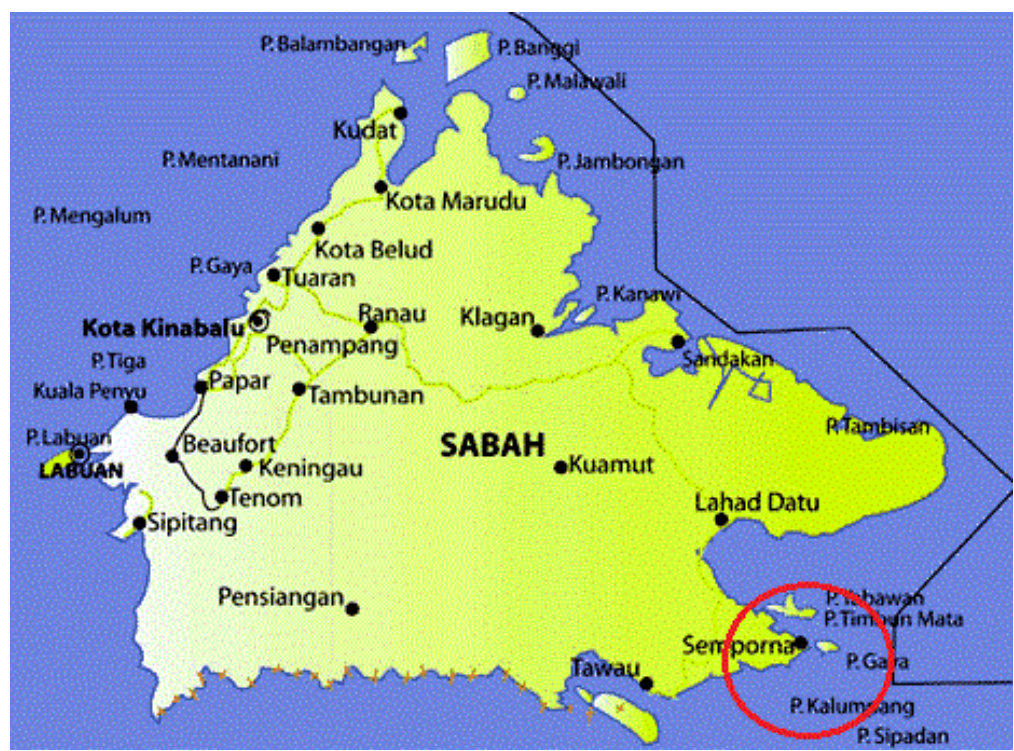

Figure 1: Sabah sea area (Red circle shows the sampling area).

\section{RESULTS}

This study describes the antimicrobial and antioxidant activities of marine actinomycetes from conserved sea area of Sipadan Island. The crude extracts of secondary metabolites from 100 strains of marine actinomycetes were tested for both assays in which only 22 and 31 strains showed antioxidants and antimicrobial activities, respectively.

\section{Antioxidant activity}

The antioxidant activities of all the crude extracts were analyzed by using DPPH assay and only 22 strains showed antioxidant activities. The percentage of DPPH scavenging activities of all five different concentrations for each extracts were calculated and the IC50 values of the secondary metabolites from the 22 strains extracts were determined (Table 1). The IC50 values of the 22 extracts ranged from 56 $\mu \mathrm{g} / \mathrm{ml}$ to $99 \mu \mathrm{g} / \mathrm{ml}$, in which the most remarkable value was exhibited by strain MSA07 with $56.3 \mu \mathrm{g} / \mathrm{ml}$. It is impressive that the IC50 values of all the 22 active extracts are in the range of $\mu \mathrm{g} / \mathrm{ml}$, considering all are of their crude extracts. Though the working extracts are of crude and of low concentration, these extracts gave potent antioxidant properties when compared with ascorbic acid as the standard antioxidant.

From all of the 22 extracts, the percentage of DPPH scavenging activities increased as the concentration of extracts increased (Figure 2, 3, 4 and 5). Strong antioxidant activities were observed on the crude extracts of strain MSA07 and MSA82 with $67.81 \%$ and $71.30 \%$ of scavenging activities at $100 \mu \mathrm{g} / \mathrm{ml}$, respectively.

\section{Antimicrobial activity}

The results of the antimicrobial activities are shown in Table 2. From 100 strains tested, 31 strains showed antimicrobial activities against the test pathogens. The most prominent finding in this assay was the abilities of the marine actinomycetes strains to inhibit more than just one pathogen. Out of 31 bioactive strains, 24 strains exhibited antimicrobial activities against at least two pathogens, in which four strains such as MSA18, MSA23, MSA26 and MSA62 successfully inhibited up to five strains of pathogens. The data also showed that the numbers of strains that were able to inhibit 
gram positive bacteria (Bacillus cereus, Bacillus subtilis, Staphylococcus aureus, Streptococcus pyogenesand Streptococcus pneumonia) were higher compared to the gram negative bacteria (Escherichia coli, Klebsiella spp. and Pseudomonas aeruginosa). Staphylococcus aureus was the most susceptible pathogen, in which 16 extracts of marine actinomycetes strains were able to inhibit this pathogen. On the other hand, Escherichia coli appeared to be the least susceptible pathogens with only eight extracts have antimicrobial activities on this pathogen.

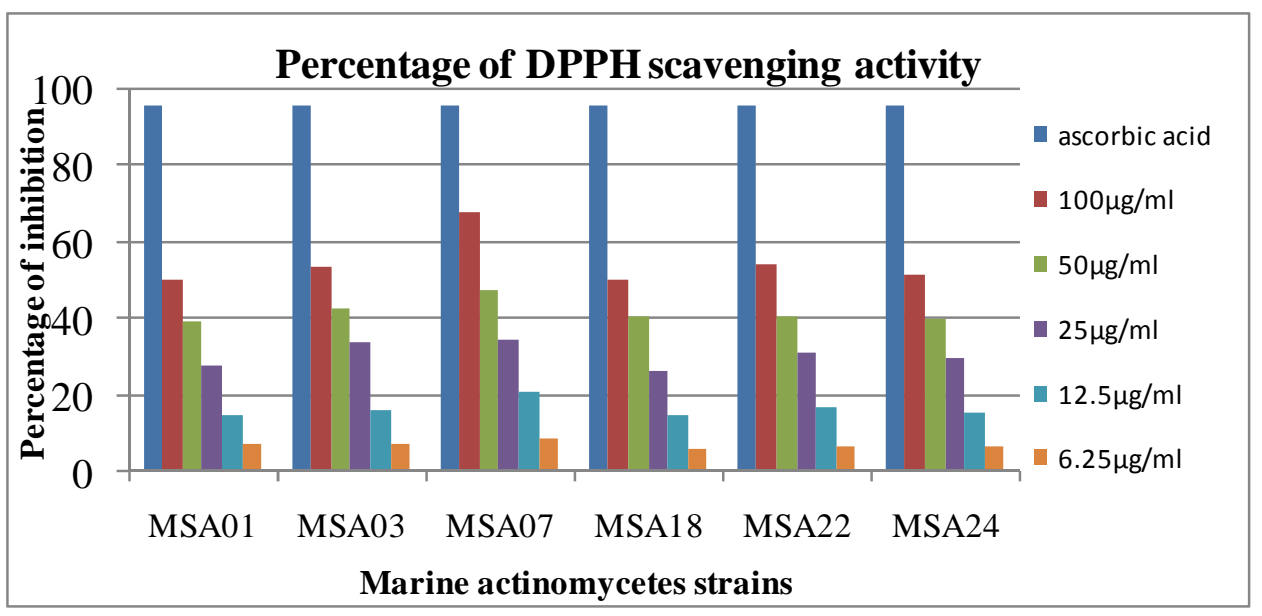

Figure 2: The DPPH scavenging activity of strains MSA01, MSA03, MSA07, MSA18, MSA22 and MSA24. All samples with different concentration are compared with ascorbic acid as antioxidant which shows $95.8 \%$ of DPPH scavenging activity at concentration of $100 \mu \mathrm{g} / \mathrm{ml}$.

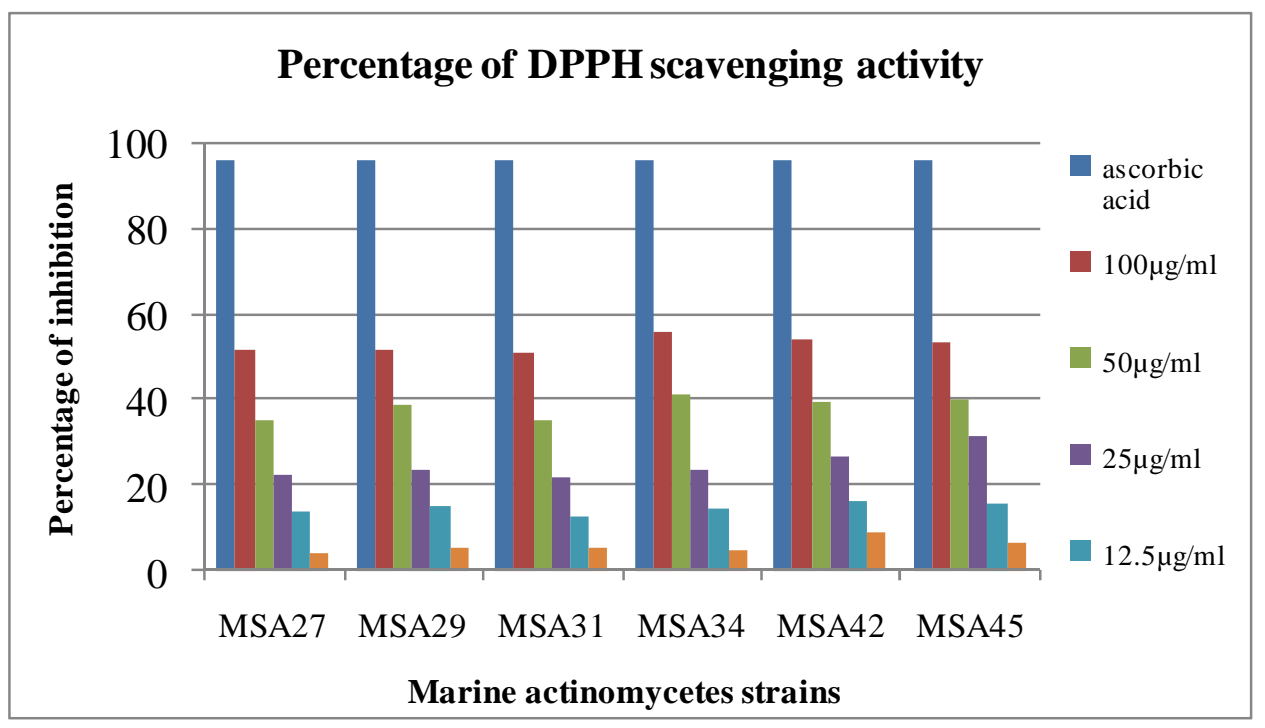

Figure 3: The DPPH scavenging activity of strains MSA27, MSA29, MSA31, MSA42 and MSA45. All samples with different concentration are compared with ascorbic acid as antioxidant which showed $95.8 \%$ of DPPH scavenging activity at concentration of $100 \mu \mathrm{g} / \mathrm{ml}$. 


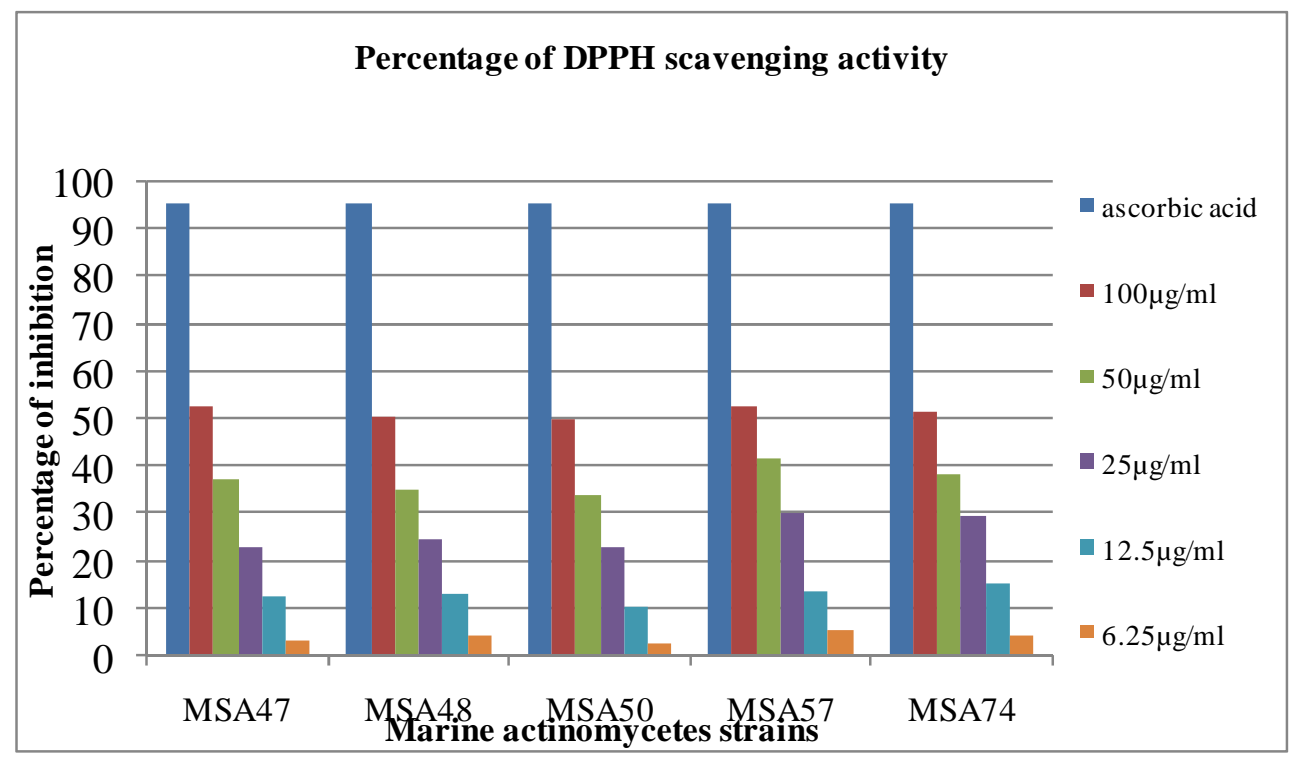

Figure 4: The DPPH scavenging activity of strains MSA47, MSA48, MSA50, MSA57 and MSA74. All samples with different concentration are compared with ascorbic acid as antioxidant which showed $95.8 \%$ of DPPH scavenging activity at concentration of $100 \mu \mathrm{g} / \mathrm{ml}$.

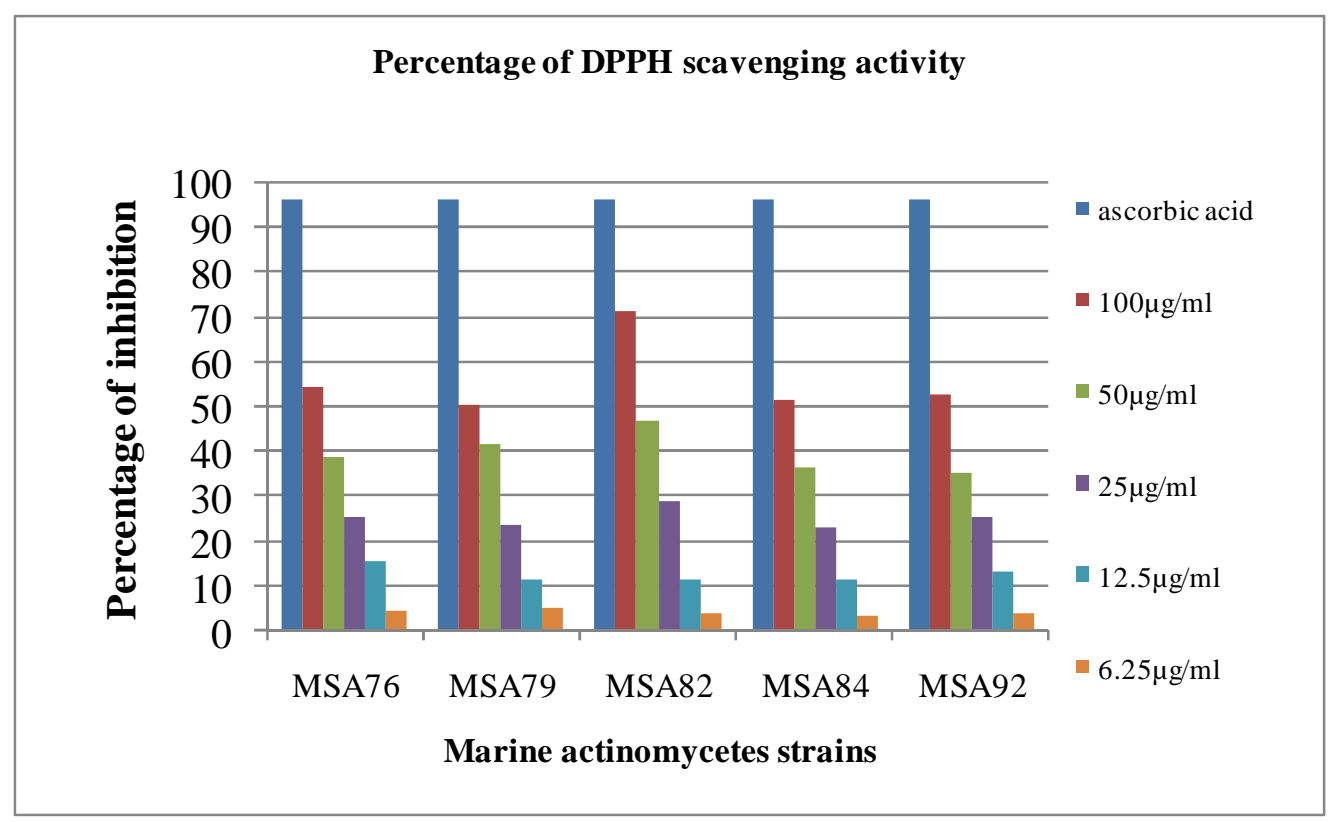

Figure 5: The DPPH scavenging activity of strains MSA76, MSA79, MSA82, MSA84 and MSA92. All samples with different concentration are compared with ascorbic acid as antioxidant which showed $95.8 \%$ of DPPH scavenging activity at concentration of $100 \mu \mathrm{g} / \mathrm{ml}$. 
M. bin A. B. AIZUDDIN et al. / Int. J. Biol. Chem. Sci. 7(2): 750-759, 2013

Table 1: $\mathrm{IC}_{50}$ values of antioxidant activity.

\begin{tabular}{lc}
\hline Strains & IC $_{\mathbf{5 0}}(\boldsymbol{\mu g} / \mathbf{m l})$ \\
\hline MSA01 & 98.2 \\
MSA03 & 95.4 \\
MSA07 & 56.3 \\
MSA18 & 97.1 \\
MSA22 & 89.3 \\
MSA24 & 98.6 \\
MSA27 & 98.0 \\
MSA29 & 97.2 \\
MSA31 & 97.9 \\
MSA34 & 79.5 \\
MSA42 & 91.4 \\
MSA45 & 90.1 \\
MSA47 & 85.0 \\
MSA48 & 98.5 \\
MSA50 & 99.1 \\
MSA57 & 78.5 \\
MSA74 & 92.1 \\
MSA76 & 85.5 \\
MSA79 & 96.4 \\
MSA82 & 56.8 \\
MSA84 & 91.4 \\
MSA92 & 95.2 \\
\hline values in $\mu$ g/ml.MSA = Marine Sponge Actinomycetes.
\end{tabular}

$\mathrm{IC}_{50}$ values in $\mu \mathrm{g} / \mathrm{ml} . \mathrm{MSA}=$ Marine Sponge Actinomycetes 
Table 2: Antimicrobial activity of marine actinomycetes.

\begin{tabular}{|c|c|c|c|c|c|c|c|c|}
\hline \multirow{2}{*}{ Strains } & \multicolumn{8}{|c|}{ Antimicrobial assay (mm) } \\
\hline & STAPH A & STREP A & KLEB & B.C & B.S & S.P & E.C & P.A \\
\hline MSA01 & $9 \pm 0.6$ & 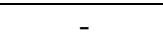 & - & $10 \pm 0.0$ & - & - & - & - \\
\hline MSA03 & $12 \pm 0.0$ & $11 \pm 0.0$ & - & - & - & - & - & - \\
\hline MSA07 & $9 \pm 0.0$ & - & $10 \pm 0.0$ & - & $8 \pm 0.0$ & - & - & $12 \pm 0.0$ \\
\hline MSA09 & $8 \pm 0.0$ & - & - & $9 \pm 0.0$ & $12.3 \pm 0.6$ & - & - & - \\
\hline MSA15 & - & - & - & $12.3 \pm 0.6$ & $-10 \pm 0.0$ & - & - & $10 \pm 0.0$ \\
\hline MSA18 & $8 \pm 0.0$ & $8 \pm 0.0$ & - & $8 \pm 0.0$ & $8 \pm 0.0$ & - & - & $8+0.0$ \\
\hline MSA22 & $10 \pm 0.0$ & $19 \pm 0.0$ & - & - & $9 \pm 0.0$ & - & - & - \\
\hline MSA23 & $9 \pm 0.0$ & $11 \pm 0.0$ & $8 \pm 0.0$ & $8 \pm 0.0$ & $10 \pm 0.0$ & - & - & - \\
\hline MSA26 & $10 \pm 0.0$ & $10 \pm 0.0$ & - & $10 \pm 0.0$ & $10 \pm 0.0$ & $10 \pm 0.0$ & - & - \\
\hline MSA34 & $8 \pm 0.0$ & $9 \pm 0.0$ & - & - & - & - & - & - \\
\hline MSA36 & - & - & - & $10.3 \pm 0.6$ & $11 \pm 0.0$ & $8+0.0$ & $9 \pm 0.0$ & - \\
\hline MSA37 & $9.3 \pm 0.6$ & - & $9 \pm 0.0$ & - & - & - & $10 \pm 0.0$ & - \\
\hline MSA41 & - & - & $11 \pm 0.0$ & - & - & $9 \pm 0.0$ & $8 \pm 0.0$ & - \\
\hline MSA44 & $9 \pm 0.0$ & $9 \pm 0.0$ & - & - & - & - & - & - \\
\hline MSA46 & $10 \pm 0.0$ & $9 \pm 0.0$ & $11 \pm 0.0$ & - & - & - & - & - \\
\hline MSA49 & - & - & - & $14 \pm 0.0$ & $10 \pm 0.0$ & $10 \pm 0.0$ & - & - \\
\hline MSA52 & - & - & - & - & - & - & $11 \pm 0.0$ & $13 \pm 0.0$ \\
\hline MSA57 & - & - & - & - & - & $10 \pm 0.0$ & - & - \\
\hline MSA60 & $10 \pm 0.0$ & $10 \pm 0.0$ & - & - & - & $13 \pm 0.0$ & - & - \\
\hline MSA62 & $9 \pm 0.0$ & $10 \pm 0.0$ & - & $14 \pm 0.0$ & $10 \pm 0.0$ & $10 \pm 0.0$ & - & - \\
\hline MSA65 & & & & & & $11 \pm 0.0$ & $13 \pm 0.0$ & $8 \pm 0.0$ \\
\hline MSA68 & & & $11 \pm 0.0$ & & & & & \\
\hline MSA69 & $9 \pm 0.0$ & $10 \pm 0.0$ & $11 \pm 0.0$ & & & & & \\
\hline MSA73 & $8 \pm 0.0$ & $11 \pm 0.0$ & & $10 \pm 0.0$ & $13 \pm 0.0$ & & & \\
\hline MSA77 & & & $9 \pm 0.0$ & & & $12 \pm 0.0$ & & $15 \pm 0.0$ \\
\hline MSA79 & $13 \pm 0.0$ & $13 \pm 0.0$ & $13 \pm 0.0$ & & & & & $14 \pm 0.0$ \\
\hline MSA82 & & $10 \pm 0.0$ & & $11 \pm 0.0$ & $14 \pm 0.0$ & & & \\
\hline MSA84 & & & $13 \pm 0.0$ & & & & $10 \pm 0.0$ & $12 \pm 0.0$ \\
\hline MSA95 & $12 \pm 0.0$ & $13 \pm 0.0$ & $12 \pm 0.0$ & & & & & $8 \pm 0.0$ \\
\hline MSA98 & & & & $13 \pm 0.0$ & & & $9 \pm 0.0$ & $9 \pm 0.0$ \\
\hline MSA99 & $12 \pm 0.0$ & $15 \pm 0.0$ & & & & & $8 \pm 0.0$ & \\
\hline
\end{tabular}

\section{DISCUSSION}

The data from this research confirmed the therapeutic potential of marine actinomycetes from the conserved sea area of Sipadan Island as they possess strong antioxidant and antimicrobial activities in their crude secondary metabolites. This study has demonstrated for the very first time that the marine actinomycetes from this pristine sea area do possess great pharmaceutical value.

Other marine actinomycetes isolated from other region of the world also exhibited antioxidant activities. A compound known as Diazepinomidin have been isolated from marine sponges-associated strains Micromonospora sp. RV115 and it exhibited significant antioxidant and protective capacity from genomic damage induced by the reactive oxygen species hydrogen peroxide in human kidney (HK-2) and human promyelocytic (HL-60) cell lines (Abdelmohsen et al., 2012). In addition, the secondary metabolites of Streptomyces sp. VITTK3 from marine soil sample collected at the Bay of Bengal, India also has the antioxidant activities on DPPH 
assay (Kannabiran et al., 2010). The data in this study showed that the marine actinomycetes isolated from Sipadan Island have great antioxidant potential as the IC50 values of all the active crude extracts were only in the low concentration range of $\mu \mathrm{g} / \mathrm{ml}$.

The ability of marine actinomycetes strains isolated from Sipadan Island to inhibit the growth of multiple pathogens only by using $30 \mathrm{mg} / \mathrm{ml}$ crude extracts may provide the alternative for the development of new antimicrobial drugs. Recently, marine actinomycetes have become an important source for the development of new antimicrobial drugs worldwide, in which novel antimicrobial compounds such as Abyssomicin $\mathrm{C}$ and Lactonamycin have been discovered from these marine microbes (Matsumoto et al, 1999; Bister et al., 2004; Lam, 2006). Despite this potential, this study is the first that revealed the antimicrobial properties of marine actinomycetes from the conserved sea area of Sipadan Island.The finding in this study is crucial for the effort to cure bacterial infection in human population, given that the current treatments of bacterial infections are really difficult and challenging due to the ability of bacteria to develop resistance towards the currently available antibiotic drugs (Tanaka et al., 2006; Tenover, 2006).

This study demonstrated that there are a total of 10 strains that showed activity on both antioxidant and antimicrobial assays. They are MSA01, MSA03, MSA07 MSA18, MSA22, MSA34, MSA79, MSA79, MSA82 and MSA89. This indicated that these marine actinomycetes can be a major source for new antioxidant and antimicrobial drugs by its production of secondary metabolites. The ocean has various levels of pressure, salinity and temperature depending on time and season (Olano et al., 2009).Therefore, marine actinomycetes from the sea area of Sipadan Island, which is one of the world's most primitive ocean, may exhibit a huge potential of many unknown pharmaceutical applications that are yet to be discovered since they have the ability to produce new chemical entities with diverse pharmacological activities (Lam, 2006).

\section{Conclusion}

The successful isolation of marine sponges-associated actinomycetes from Sipadan Island proved that this conserved area does have enormous marine actinomycetes diversity that yet to be discovered. The novel discovery of remarkable antioxidant and antimicrobial activities showed that it is importance to exploit the actinomycetes from Sipadan Island. The antioxidant and antimicrobial activities of the active strains can be further enhanced through the purification process in the future work, and these secondary metabolites can be used as natural antioxidant and antimicrobial drugs to replace the artificial drugs that are currently available for the same treatment.

\section{REFERENCES}

Abdelmohsen UR, Szesny M, Othman EM, Schirmeister T, Grond S, Stopper H, Hentschel U. 2012. Antioxidant and AntiProtease Activities of Diazepinomicin from the Sponge-Associated Micromonospora Strain RV115. Marine Drugs, 10: 2208-2221.

Atta HM, Bayoumi R, El-Sehrawi M, Aboshady A, Al-Humiany A. 2010. Biotechnological application for producing some antimicrobial agents by actinomycetes isolates from Al-khurmah Governorate. European Journal of Applied Science, 2: 98-107.

Bister B, Bischoff D, Strobele M, Riedlinger J, Riecke A, Wolter F, Bull AT, Zahner H, Fiedler HP, Sussmuth RD. 2004. Abyssomicin C-A polycyclic antibiotic from a marine Verrucosisspora strain as an inhibitor of the p-aminobenzoic acid/ tetrahydrofolate biosynthesis pathway. Angewandte Chemie International Edition, 43(19): 2574-2576.

Brun YV, Skimkets LJ, Frey CD. 2000. Prokaryotic development. American 
Society for Microbiology Press, 13: 1131.

Carpenter KE, Springer VG. 2005. The center of the center of marine shore fish biodiversity: The Philippines Islands. Environmental Biology of Fishes, 72: 467-480.

De Carvalho CCR, da Fonseca MMR. 2006. Biotransformation of terpenes. Biotechnology Advanced, 24: 134-142.

De Carvalho CCR, Fernandes P. 2010. Production of Metabolites as Bacterial Responses to the Marine Environment. Marine Drugs, 8: 705-727.

Berdy J. 2005. Bioactive microbial metabolites.The Journal of Antibiotics, 58: $1-26$.

Kannabiran K, Sindhura S, Thenmozhi M. 2010. Characterization of Antioxidant activity of Streptomyces species VITTK3 isolated from Puducherry Coast, India. International Journal of Advanced Scientific Research, 1(2): 46-52.

Kekuda TRP, Shobha KS, Onkarappa R. 2010. Fascinating diversity and potent biological activities of actinomycetes metabolites. Journal of Pharmacy Research, 3: 250-256.

Lam KS. 2006. Discovery of novel metabolites from marine actinomycete. Current Opinion Microbiology, 9: 245251.

Matsumoto N, Tsuchida T, Maruyama M, Kinoshita N, Homma Y, Sawa HT, Hamada M, Takeuchi T, Heida N, Yoshioka T. 1999. Lactonamycin, a new antimicrobial antibiotic produced by
Streptomyces rishiriensis MJ773-88K4 I. Taxonomy, fermentation, isolation, physic-chemical properties and biological activities. Journal of Antibiotic, 52: 269275.

Naine J, Srinivasan MV, Devi SC. 2011. Novel anticancer compounds from marine actinomycetes. J. Pharm. Res., 4: 12851287.

Olano C, Mendez C, Jose AS. 2009. Antitumor Compounds from Marine Actinomycetes. Marine Drugs, 7(2): 210248.

Pham-Huy LA, Hua He H, Pham-Huy C. 2008. Free Radicals, Antioxidants in Disease and Health. International Journal of Biomedial Science, 4(2): 89-96.

Sengupta S. Chattopadhyay MK. 2012. Antibiotic Resistance of Bacteria: AGlobal Challenge. Resonance, 17: 177191.

Spadi F. 2003. PulauLigitan and PulauSipadan: New Parameters for the Concept of Dependency in the Maritime Environment?. The International Journal of Marine and Coastal Law, 18: 295-310.

Tanaka JCA, da Silva CC, de Oliveira AJB, Nakamura C, DiasFilho BP. 2006. Antibacterial activity of iodole alkaloids from Aspidosperma ramifloram. Brazilian Journal of Medical And Biological Research, 39(3): 387-391.

Tenover FC. 2006. Mechanisms of Antimicrobial Resistance in Bacteria. The American Journal of Medicine, 119: 310 . 